\title{
Development and Evaluation of Global Positioning System Science Lesson Based on Science, Technology, Engineering, and Mathematics Model in Singapore
}

\author{
Shuichi Yamashita ${ }^{1 *}$, Jennifer Yeo $^{2}$, Kei Nakanishỉ ${ }^{3}$, Kentaro Kojima ${ }^{4}$, Risa Igarashi ${ }^{4}$, Asami Terasawa ${ }^{4}$, Janessa Chang², \\ Jeshrei Toh², Aaron Pang'², Sapto Ashardianto', Jun Nomura ${ }^{1}$ \\ ${ }^{1}$ Department of Science Education, Faculty of Education, Chiba University, Chiba, Japan, ${ }^{2}$ Department of Science Education, National Institute of \\ Education, Nanyang Technological University, Singapore, ${ }^{3}$ Department of Urban Environment Systems, Graduate School of Engineering, Chiba \\ University, Chiba, Japan, ${ }^{4}$ Department of Education, Chiba University, Chiba, Japan
}

*Corresponding Author: syama@faculty.chiba-u.jp

\section{ABSTRACT}

The purpose of the Twin College Envoys (TWINCLE) program for Chiba University students was to visit secondary schools of the Association of Southeast Asian Nation countries and provide science lessons on cutting-edge technology. The focus of this research was to develop a learning program contextualized around the Global Positioning System (GPS) using the Science, Technology, Engineering, and Mathematics (STEM) model for Singapore students and to evaluate the science lessons. In total, 53 high school students received 100 min of instruction using two experiments with worksheets as part of the TWINCLE program, and then, they were asked to answer a questionnaire. The research yielded the following three results. First, by the end of the lesson, the students could explain how the GPS worked and list the benefits of GPS surveying. Second, the teaching materials and hands-on activities were well-received by the students and our Singapore counterparts. Finally, the science lesson based on STEM model was highly evaluated and awarded the 2017 best TWINCLE prize. In the future, it is recommended the TWINCLE program should be continued and funded by Chiba University to promote global opportunities for university students and teachers.

KEY WORDS: global positioning system; science, technology, engineering, and mathematics; Twin College Envoys program; Singapore

\section{INTRODUCTION}

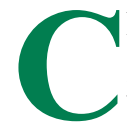

hiba University has been funded by the Japanese government since 2012 to promote global talent. Undertaking this task is the Department of Education which designed and developed the Twin College Envoys (TWINCLE) program for university students to promote globalization. In this program, students of Chiba University whose majors are education and other subjects, visit primary and secondary schools of the Association of Southeast Asian Nation (ASEAN) countries, and provide science lessons on cutting-edge science, technology, and Japanese culture (e.g., Nomura et al., 2017). The effectiveness of the program is evaluated on two aspects: (1) The undergraduate students' capability to design an effective activity to promote the science and technology in Japan and its culture and (2) the undergraduate students' capability to communicate effectively in English.

This paper reports the $3^{\text {rd }}$ year of implementation of the TWINCLE program, focusing on its implementation in Singapore schools. In the earlier phases of the program, it was noted that school students tend to be less familiar with how the science content learnt in school might be relevant to the technology they are familiar with in their daily lives. One example was noted by Yamashita et al. (2017) in their description of a science lesson improvement process conducted in Singapore in 2015. To address this issue, Chiba University students created a science lesson on the Global Positioning System (GPS) in 2017 using the framework of Science, Technology, Engineering, and Mathematics (STEM) for the Singaporean high school context. GPS is a key component of automatic driving. In recent years, GPS location information has become accurate to within an error margin at the centimeter level. This level of accuracy is expected by the Quasi-Zenith Satellite System (QZSS, nicknamed "MICHIBIKI") launching in Japan. It is expected that MICHIBIKI will become a 4-satellite constellation in 2018 and a 7-satellite constellation around 2023. From conversations with Singapore counterparts, it was understood that while Singapore school students were familiar with maps and navigation using GPS; however, many might not understand how the GPS on their smartphone works. There are also very few science education research studies on the mechanisms of GPS, even when including the research, which treats GPS as a device (e.g., March 2012). In contrast, Discovery Education is offering STEM for the classroom that features GPS and navigation (Discovery Education, 2013). In this study, a 100-min activity was designed using the STEM model to explain the mechanism of GPS to Singaporean Grade 9-12 students (students aged 14-18). The learning program was conducted at two Singapore schools as part of the TWINCLE program and 
evaluated for its effectiveness. More specifically, the aims of the study were to:

1. Develop a learning program contextualized around GPS using the STEM model for Singaporean students.

2. Evaluate science lessons in English using questionnaires and Singaporean counterpart comments.

3. Evaluate the science lessons through the TWINCLE International Conference poster session.

\section{LITERATURE REVIEW}

The acronym STEM, which stands for science, technology, engineering, and mathematics, carries different meanings to different (groups) of people (Czerniak and Johnson, 2014). While it might be considered as a shorthand way of making references to the four individual disciplines by some (Breiner et al., 2012), this paper takes the view that STEM refers to the integration of the four disciplines (Sanders, 2009). Among the integrative perspective, there are multiple models of integration - discipline specific, content specific, skills and processes, methodology, and thematic (Davidson et al., 1995).

This study adopted a thematic approach around the theme of GPS, with the selection and organization of content and skills aimed at developing high school students' understanding of how GPS works. These included the science content of waves, mathematics content related to scale and geometry, and engineering skills of surveying, mapping, and calibration, and the use of technology such as the use of a GPS logger for calibration. The STEM activity was organized as a challenge - to develop the most accurate map of the school. The specifics of the activities are described in the following sections. It was hypothesized that such integrated activities should bring about an increase in these high school students' interest and achievement in learning (Stevenson and Carr, 1993). As the supervising university researchers, we hypothesized that the multidisciplinary teamwork among the university students would lead to a gain in English communication skills as well as in the competencies in integrating the knowledge of STEM and pedagogical knowledge.

\section{METHOD}

\section{Design and Participants}

The GPS activity was conducted in two secondary schools in Singapore. In School A (a public school), 31 Grade 10 students participated in the 100-min GPS learning activity on March 6,2017 , as part of their enrichment activity for higher ability students in the school. In School B (a partially governmentfunded school), 22 Grade 10 students volunteered to participate in the activity on March 7, 2017. Participation is optional. Only field notes were taken. Permission to conduct anonymized survey was obtained from the schools' key personnel. As each Singapore school follows a structured timetable of about 6-7 h, timetabled time is typically needed to complete the syllabuses. As such, activities such as this GPS activity are typically conducted after school hours as part of students' enrichment activities.
The students were divided into groups of three, and the 100min learning activity was carried out at both A and B schools (Table 1).

\section{Objectives}

By the end of the lesson, student should be able to explain how GPS works and identify the benefits of GPS surveying.

\section{Questionnaire}

Students were asked to answer questionnaires Q1 and Q2 after the learning program.

Q1: How do you evaluate the handouts/materials by the lecturers in your class?

Q2: How do you evaluate the lectures, experiments, or activities in your class?
1. All of them were good
2. Many of them were good
3. Fair
4. Many of them were poor
5. All of them were poor

Please explain briefly:

\section{GPS Learning Program}

The learning program was developed using the STEM model for Singaporean students by four Japanese students (Engineering master student: A, Science education student: B, and English education students: C and D) as part of the TWINCLE program. The learning program was revised by the Singaporean counterparts (Supervisor: SA and Science education students: SB, SC, and SD) for a week at the local teacher training institute.

GPS specifies the position by calculating the distance of the satellite and the receiver from information sent by other space satellites. To help students understand these mechanisms, we created a model to demonstrate how GPS operates and two experimental activities with accompanying worksheets (WS).

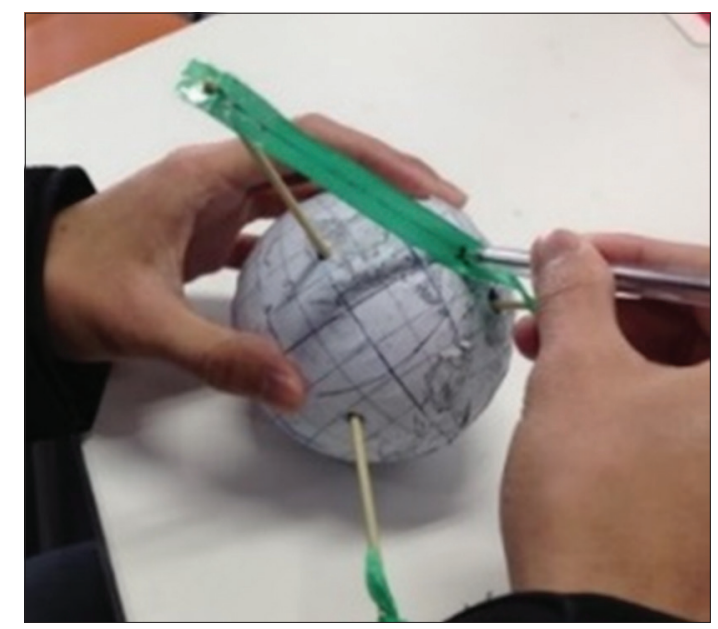

Figure 1: GPS model 


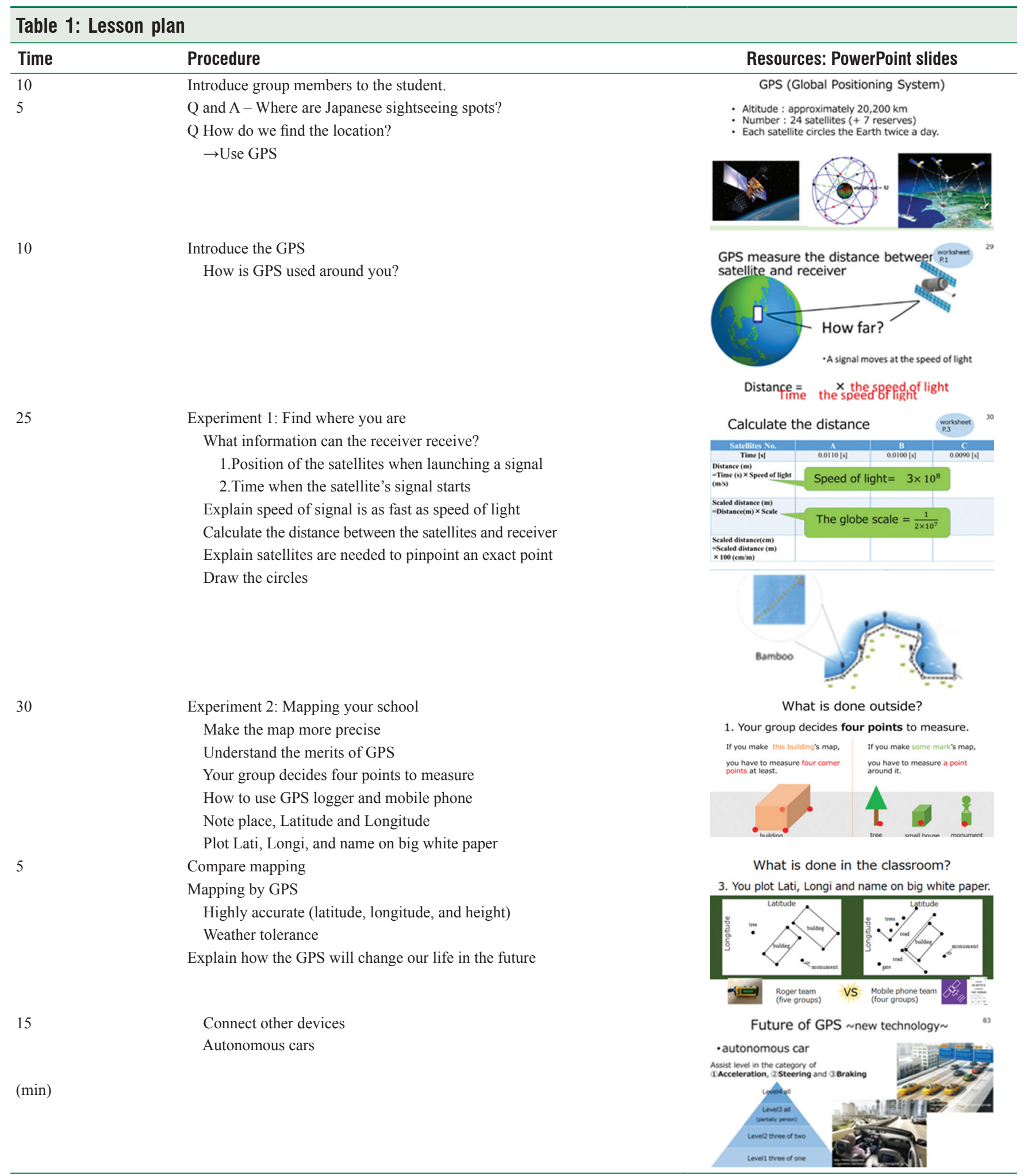

\section{GPS model}

If you know the position of the three satellites, you can locate the position of the receiver. We developed the GPS model to explain this mechanism (Figure 1). A bamboo skewer was used to pierce the globe model composed of a world map on a spheroidal piece of styrene foam. The bamboo skewer correlated with the position of a satellite. It was pointed out that the point where the three circles drawn from each of the three satellites intersected was the present location of the receiver. 


\section{Experiment 1: Find where you are}

The receiver's present location point was determined using the model according to the following procedures (1-4).

1. The distance from each satellite to the receiver was calculated as well as the time that the signal took to reach the receiver. The numerical value was matched to the same scale of the GPS model (Figure 2).

2. The ruler was matched to the ribbon, and an " $x$ " was drawn in the ribbon according to the calculations in step (1).

3. The pen was inserted into the ribbon at " $\times$." With the ribbon pulled taut, a circle was drawn using the pen on the globe (Figure 3).

4. Steps (1), (2), and (3) were repeated for each of the three satellites. Locating where all three circles intersected, the students were able to determine the receiver's location (Figure 4).

\section{Experiment 2: Mapping your school}

A map of the school building was made using both a GPS logger and a smartphone to explore the advantages of GPS.

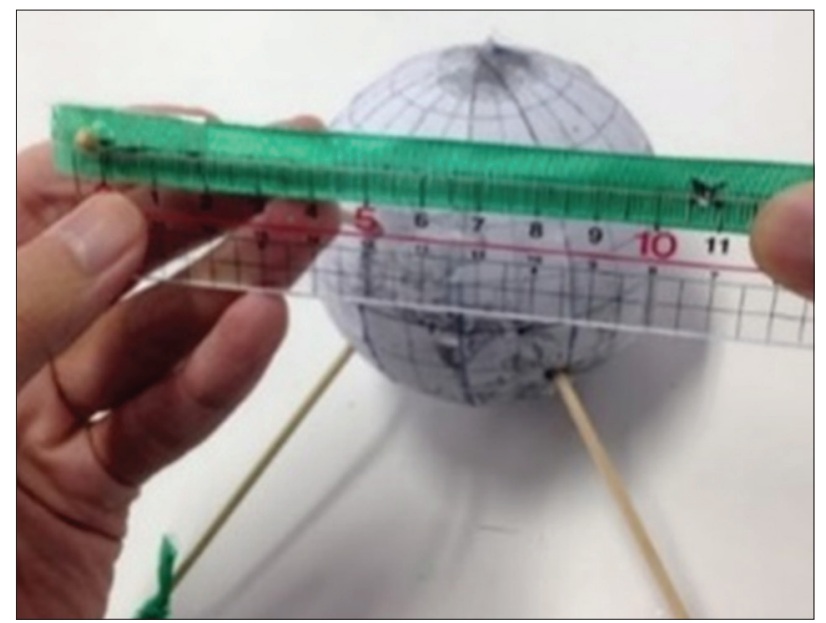

Figure 2: Operation of the Global Positioning System model

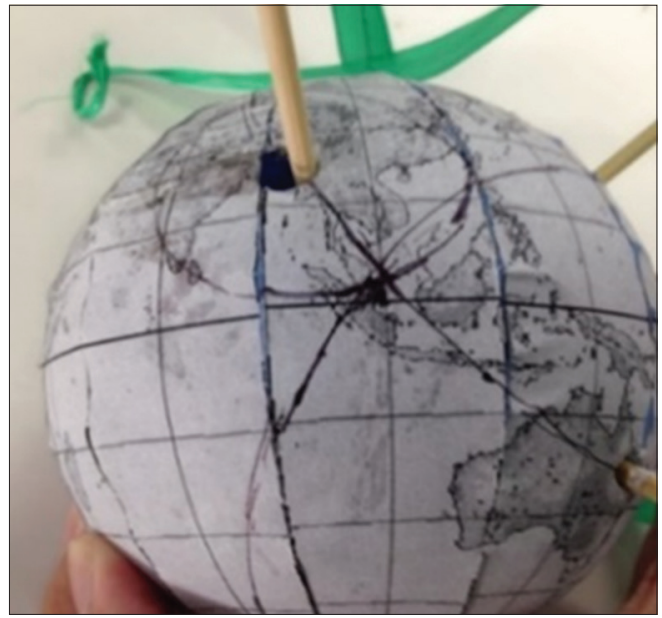

Figure 3: Drawing a circle on the globe
Because the applications on a smartphone might not be able to draw the shape of the schoolhouse, we also used a GPS logger and were able to compare the accuracy between them. First, we introduced the method of making an old map and compared with GPS. Students were divided into a GPS logger team and smartphone team (Figure 5).

Afterward, the Singaporean students went out to the schoolyard and determined the location and dimension information of the schoolhouse (Figure 6). They then returned to the classroom to make the map of the schoolhouse (Figure 7).

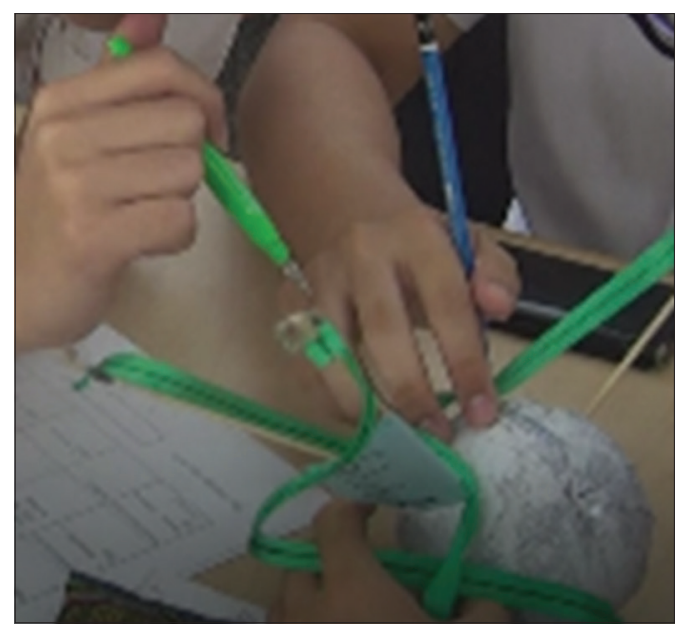

Figure 4: Determining present place

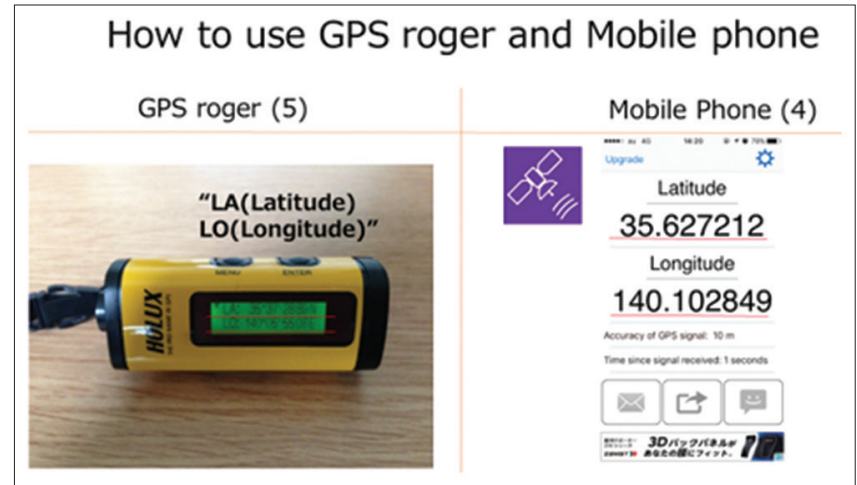

Figure 5: Global Positioning System logger team and smartphone team

\section{What is done outside?}

2. You note Place, Latitude and Longitude.

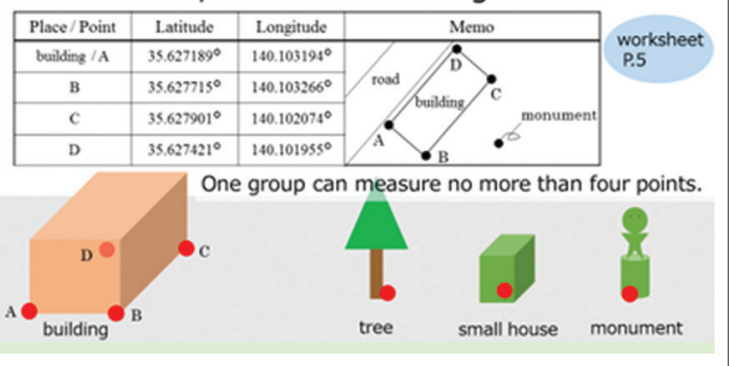

Figure 6: Acquiring information of the schoolhouse 


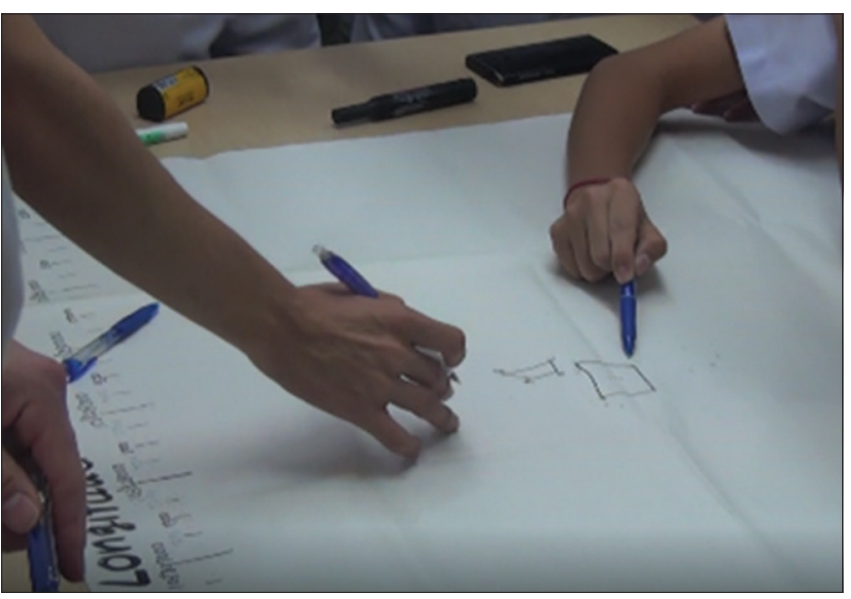

Figure 7: Making the map of the schoolhouse

Table 2: Answers and means of Q1 and Q2 (A school: 31, B school: 22)

\begin{tabular}{lccccc}
\hline \multirow{2}{*}{ Answer } & \multicolumn{2}{c}{ Q1: materials } & & \multicolumn{2}{c}{ Q2: lecture } \\
\cline { 2 - 3 } \cline { 5 - 6 } & A school & B school & & A school & B school \\
\hline (1) All good & 18 & 16 & & 20 & 14 \\
(2) Many good & 12 & 3 & & 10 & 4 \\
(3) Fair & 1 & 3 & & 1 & 4 \\
(4) Many poor & 0 & 0 & & 0 & 0 \\
(5) All poor & 0 & 0 & & 0 & 0 \\
Mean (SD) & $1.45(0.57)$ & $1.39(0.56)$ & & $1.41(0.73)$ & $1.55(0.80)$ \\
\hline
\end{tabular}

\section{RESULTS}

\section{Evaluation using the Questionnaires}

Table 2 shows the Schools A and B student's answers and means of questionnaires. There was not a significant difference in the means between schools (Q1: $\mathrm{t}(51)=0.238$ n.s.; Q2: $\mathrm{t}$ $(35.082)=0.800$ n.s. $)$.

Most students selected (1) all good or (2) many good with the reasons such as "Activity was fun," "It was interesting," and "Teaching way, Teaching material, and WS were comprehensible" though there were many mistakes in the English explanation. However, some students answered (3) fair for the reason "Activity was very hard" and "Want to know more detail."

\section{Evaluation from Singapore Counterpart Comments}

Table 3 shows the comments of SA, SB, SC, and SD about the science lesson. Although SA mentioned the improvement of the science lesson in English, SA, SB, SC, and SD said "(a) The relation to STEM and daily life was considered," "(b) Activity, teaching material, and WS were devised," and "(c) Zeal for the science lesson" in the parts of underline as shown in Table 3. Moreover, SB and SC said "(d) Working together once again." SC also mentioned "(e) Meaning of TWINCLE program that engineering graduate student and education student work together to develop science lessons in English."

\section{Table 3: Singapore counterpart comments}

\section{SA Strengths:}

1. (a) A good lesson that incorporates science and engineering/technology. Students will be able to see how the scientific concepts that they learn in class are applicable to their everyday life. Other concepts that can be highlighted include Doppler effect, mathematics concepts of circles.

2. (b) Interesting hands-on activities: The globe activity helped students to experience the "theory" behind how GPS locate position. The map activity helped students to construct a map of their own school - more familiarity.

3. Resources: the resources provided for the students (e.g., Globe) are well-designed and made.

4. Clarity of ideas: The lesson was conducted pretty clearly to the students.

5. (c) Enthusiasm of the teachers, especially Kentaro.

Some areas for improvement:

1. Might wish to highlight the scientific concepts a little more.

2. When speaking with the class, teachers could face the students more.

3. A little more wait time when asking questions.

4. Some parts of the lesson could have been gone through a bit faster or made more clearly without too much repetition (e.g., instructions)

SB Working with them has been a really enjoyable experience. (c) They had a well thought out plan and also receptive to comments during the preparation. All their hard work paid off in the classroom. (b) The students displayed interest in the lesson and were participative in all the activities. They were always on their feet, attending to groups which needed help and making sure to inject a little humor to engage the students. (d) I hope to be able to work with them again in the future.

SC (a) Their lesson plan showed a well thought out flow, making use of the student's prior knowledge of math and science to clearly explain how the GPS works to the students. (c) They did very well engaging the students, getting them to participate actively throughout the $2 \mathrm{~h}$ of lessons. (d) Throughout the short few days of working with the Japanese students, it was a pleasant experience interacting and working with them. I really hope to see them again next year with brand new ideas to share with our students!

SD (c) I think it was very impressive how the team managed to convey the essence of how the GPS works so simply to the students. (b) The miniature model of the globe GPS really helped students fully understand how the GPS works in real life and (a) made the realization of certain aspects of the GPS really come alive for the students (e.g., how even a tiny time inaccuracy would result in the GPS identifying a location in a completely different country!) It was also great how their plan further extended to show how technology (specifically GPS) has bettered our lives today and how continued research in the area will continue to better society.

Finally, although unrelated to the lesson per se, (e) I think the TWINCLE group, comprising students with the various expertise coming together (English language, science education, and engineering), really increased the possibilities of what they could do. It also modeled what "real-world" projects are like which I think was a very meaningful experience for the group as well for myself through my interactions with them. 


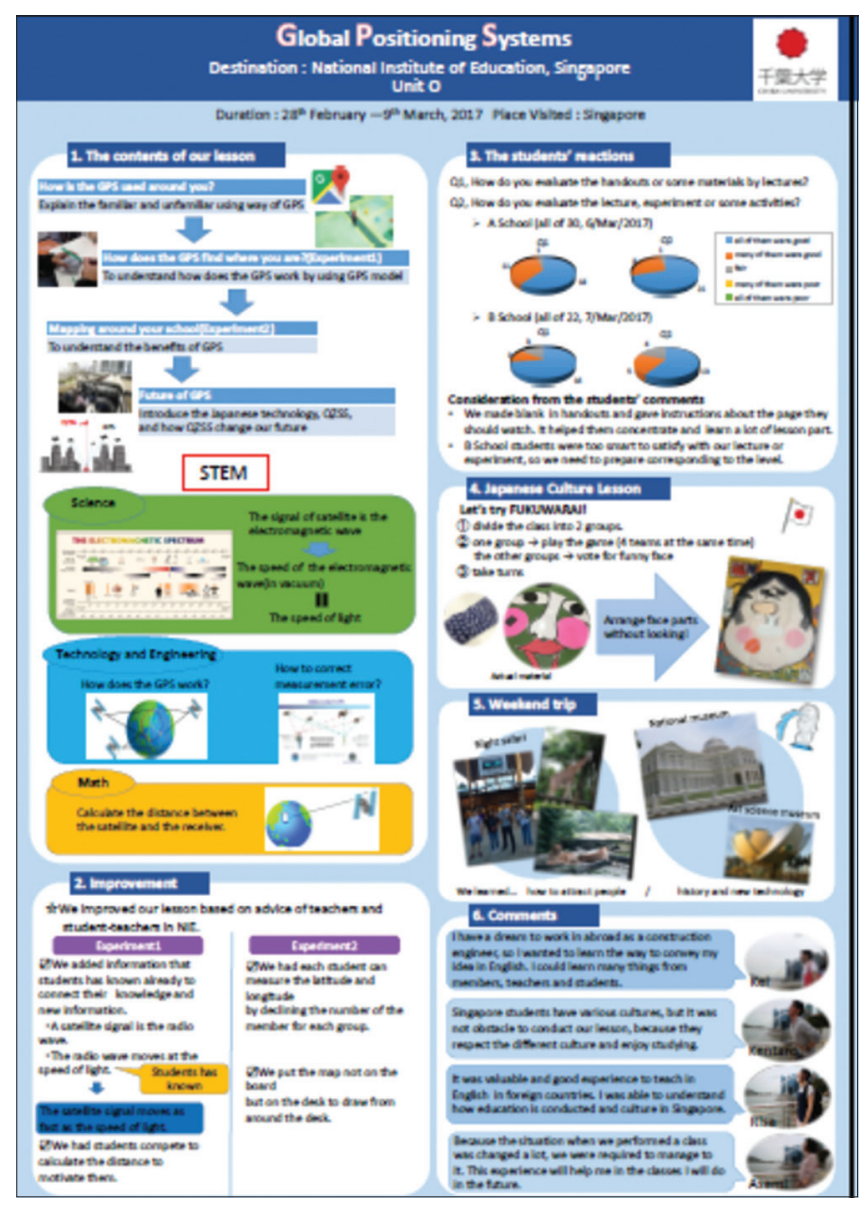

Figure 8: 2017 Best Twin College Envoys prize poster

\section{Evaluation by TWINCLE International Conference 2017}

A TWINCLE International Conference was held at Chiba University in March 2017. Fifteen groups that include those who went to other ASEAN countries participated in the poster session in English, and they were evaluated by professors from ASEAN countries on their ability to communicate in English, the effectiveness, and innovativeness of their lesson design. Each professor watched all the poster presentations and voted for two excellent groups presentations. Our groups' presentation attracted 20 votes ( $2^{\text {nd }}$ group received 11 votes) and won the 2017 Best TWINCLE prize (Figure 8). The overall winning reason was the presentation highlighted how the students were able to understand the mechanism of GPS using the GPS model and the framework of STEM.

\section{DISCUSSION AND CONCLUSIONS}

In this research, we developed a learning program contextualized around GPS using the STEM model for Singapore students and evaluated these science lessons in two Singapore high schools as part of the TWINCLE program. By the end of the lesson, students could explain how GPS works and list the benefits of GPS surveying. The teaching materials and hands-on activities were well-received by the students and our
Singapore counterparts. In addition, the science lesson based on the STEM model was highly regarded and awarded the 2017 Best TWINCLE prize. This award bore evidence of the undergraduate students' capability to communicate effectively in English as well as their competence to integrate the individual knowledge of STEM and pedagogical knowledge in a learning activity on GPS.

Funding for the TWINCLE program by the Japanese government ended in March 2017. The final evaluation by the government was the top-ranking S: "The achievement situation of the match situation and the target achieved both results more than the business scheme, and the business purpose was achieved enough" (JSPS, 2018, p. 1). In the future, the TWINCLE program should be continued and funded by Chiba University to promote global opportunities for university students and teachers.

\section{ACKNOWLEDGMENTS}

A part of this research was supported by Japan Society for the Promotion of Science (JSPS) KAKENHI (B) grant numbers 15H02910 (Representative: Shuichi Yamashita) and 16H03058 (Representative: Yoshisuke Kumano).

\section{REFERENCES}

Breiner, J., Harkness, M., Johnson, C.C., \& Koehler, C. (2012). What is STEM? A discussion about conceptions of STEM in education and partnerships. School Science and Mathematics, 112, 3-11.

Czerniak, C.M., \& Johnson, C.C. (2014). Interdisciplinary science teaching. In: Lederman, N.G., \& Abell, S.K. (Eds.), Handbook of Research on Science Education. Vol. 2. New York: Routledge. p395-411.

Davidson, D.M., Miller, K.W., \& Methany, D.L. (1995). What does integration of science and mathematics really mean? School Science and Mathematics, 95(5), 226-230.

Discovery Education. (2013). STEM for the CLASSROOM GPS and Navigation. Available from: http://www.navystemfortheclassroom. com/sites/navystemfortheclassroom.com/files/lessonplan_pdf/ GPSNavigation_FinalPDF_2018.pdf. [Last accessed on 2018 Nov 13].

Japan Society for the Promotion of Science (JSPS). (2018). Post Evaluation for the FY2012 Inter-University Exchange Project. Available from: http://www.jsps.go.jp/j-tenkairyoku/data/shinsa/h24/h24_jigo kekka_201.pdf. [Last accessed on 2018 Nov 13].

March, K.A. (2012). Using GPS Technology in the Science Classroom. The American Biology Teacher, 74, 172-177.

Nomura, J., Yoshida, K., Yamano, Y., Yamashita, S., Tsuruoka, Y., Fujita, T., Komiyama, T., Oshima, R., Ashardianto, S., Baba, S., Iizuka, M., Kato, T., Kinoshita, R., Shimonagata, S., Shirakawa, K., Sugita, K., Takaki, A., Tsuji, K., Hayashi, H., Horne, B., Yamato, M., \& Yoneda, C. (2017). Analysis of the effects of a science teacher internship abroad on university students. Journal of Science Education in Japan, 41(2), 141-149.

Sanders, M. (2009). STEM, STEM Education, STE Mmania Technology Teacher, 68(4), 20-26. Available from: https://www.eric. ed.gov/?id=EJ821633. [Last accessed on 2019 Jun 17].

Stevenson, C., \& Carr, J. (1993). Integrated Studies: Dancing through Walls. New York: Teachers' College Press.

Yamashita, S., Yeo, J., Yuchi, R., Nakamura, Y., Yamada, M., Narimatsu, I., Hirano, Y., Yang, L.T., Hwee, L.C., Nomura, J., Oshima, R., Baba, S., \& Hayashi, H. (2017). Improvement of a science lesson in Singapore based on research findings in science education: Through improvement of lesson plans, power point slides, Teaching materials and worksheets. Journal of Science Education in Japan, 41(2), 96-106. 